\title{
Effective Synthesis of Silicon Carbide Nanotubes by Microwave Heating of Blended Silicon Dioxide and Multi-Walled Carbon Nanotube
}

\author{
Voo Chung Sung Tony ${ }^{a}$, Chun Hong Voon ${ }^{a *}$, Chang Chuan Lee $e^{b}$, Bee Ying Lim ${ }^{c}$, Subash Chandra \\ Bose Gopinath ${ }^{a, d}$, Kai Loong Foo ${ }^{a}$, Mohd Khairuddin Mohd Arshad ${ }^{a}$, Abdul Rahim Ruslinda ${ }^{a}$, Uda
}

Hashim ${ }^{a}$, Mohd Nordin Nashaain ${ }^{e}$, Yarub Al-Dourif,g

anstitute of Nano Electronic Engineering, University Malaysia Perlis, 01000, Kangar, Perlis, Malaysia. ${ }^{b}$ School of Manufacturing Engineering, University Malaysia Perlis, 02600, Arau, Perlis, Malaysia.

${ }^{c}$ School of Materials Engineering, University Malaysia Perlis, Jejawi, 02600 Arau, Perlis, Malaysia.

${ }^{d}$ School of Bioprocess Engineering, University Malaysia Perlis, 02600 Arau, Perlis, Malaysia.

${ }^{e}$ Advanced Materials Research Centre, Kulim Hi-Tech Park, 09000, Kulim, Kedah, Malaysia.

${ }^{f}$ Nanotechnology and Catalysis Research Center, University of Malaya, 50603 Kuala Lumpur, Malaysia. ${ }^{g}$ Physics Department, Faculty of Sciences, University Sidi-Bel-Abbes, 22000, Algeria.

Received: March 12, 2017; Revised: July 13, 2017; Accepted: August 21, 2017

Silicon carbide nanotube ( $\mathrm{SiCNTs}$ ) has been proven as a suitable material for wide applications in high power, elevated temperature and harsh environment. For the first time, we reported in this article an effective synthesis of SiCNTs by microwave heating of $\mathrm{SiO}_{2}$ and MWCNTs in molar ratio of 1:1, 1:3, 1:5 and 1:7. Blend of $\mathrm{SiO}_{2}$ and MWCNTs in the molar ratio of 1:3 was proven to be the most suitable for the high yield synthesis of $\beta$-SiCNTs as confirmed by X-ray diffraction pattern. Only SiCNTs were observed from the blend of MWCNTs and $\mathrm{SiO}_{2}$ in the molar ratio of 1:3 from field emission scanning electron microscopy imaging. High magnification transmission electron microscopy showed that tubular structure of MWCNT was preserved with the inter-planar spacing of $0.25 \mathrm{~nm}$. Absorption bands of Si-C bond were detected at $803 \mathrm{~cm}^{-1}$ in Fourier transform infrared spectrum. Thermal gravimetric analysis revealed that SiCNTs from ratio of 1:3 showed the lowest weight loss. Thus, our synthetic process indicates high yield conversion of $\mathrm{SiO}_{2}$ and MWCNTs to SiCNTs was achieved for blend of $\mathrm{SiO}_{2}$ and MWCNTs in molar ratio of 1:3.

Keywords: Silicon Carbide Nanotube, Multi-walled Carbon Nanotube, Microwave Processing, Synthesis, Vapor-Solid Reaction.

\section{Introduction}

Silicon carbide $(\mathrm{SiC})$ has attracted much attention and has being studied for the potential in many applications such as biosensors ${ }^{1}$, photo-catalysts ${ }^{2}$ and hydrogen storage ${ }^{3}$ because it possesses several excellent properties and is also an important biocompatible material ${ }^{4}$. Compared to bulk $\mathrm{SiC}$, one-dimensional (1D) semiconductor nanostructured $\mathrm{SiC}$ such as $\mathrm{SiC}$ nano-rods, nanotubes and nanowires have been studied more extensively during the last decade owing to their versatile application in fabrication of optoelectronic, electronic and sensor devices on nanometer scale ${ }^{5}$. Silicon carbide nanotubes (SiCNTs) were known as one dimensional nanostructure material along with silicon carbide nanowires. SiCNTs have advantages over carbon nanotube (CNTs) for high temperature and harsh environment applications because they possess high reactivity on exterior surfaces, facilitating sidewall decoration and greater stability at high temperature and in highly oxidative environment ${ }^{6}$.

The main method for $\mathrm{SiC}$ production is the Acheson process, which is carbothermal reduction of $\mathrm{SiO}_{2}$ by coke at

*e-mail: chvoon@unimap.edu.my $2200-2500^{\circ} \mathrm{C}^{7}$. Due to high reaction temperatures and long reaction time, the synthesized $\mathrm{SiC}$ has often large particle size and is contaminated with impurities such as oxygen and metals. SiCNTs are currently synthesized by using chemical vapor deposition $(\mathrm{CVD})^{8}$ and carbothermal reduction of the silica by using conventional heating 9 . However, both of these methods have the downsides in the synthesis of the SiCNTs such as CVD method can only synthesize small amounts of SiCNTs and resulted in the presence of impurities in the SiCNTs due to extensive use of chemical during the synthesis of SiCNTs. Meanwhile, long heating duration, slow heating rate and requirement for further purification step to remove impurities was the problem always associated with the use of conventional heating method in carbothermal reduction of silica. Additional production cost was also needed since large consumption of energy was required to for the synthesis of SiCNTs. In addition, Latu-Romain et. al ${ }^{10,11}$ in their study of synthesis of the SiCNTs from silicon nanowire ( $\mathrm{Si}$ NW) has successfully synthesized SiCNTs by hot filament $\mathrm{CVD}$ at temperature of $1100^{\circ} \mathrm{C}$ for 30 minutes using gold as catalyst. Continuous diffusion of $\mathrm{Si}$ gas into the layer of $\mathrm{SiC}$ has resulted in the formation of SiCNTs. However, the 
use of gold as catalyst incurred high cost and the need to synthesize Si NW required additional processing step which are time and energy consuming.

Recently, many researchers have ultilized microwave heating to synthesize $\mathrm{SiC}$ because of special characteristics of microwave heating in which microwave can volumetrically heat materials with favorable dielectric properties and can synthesize $\mathrm{SiC}$ with uniform grain size at higher synthesis rate and reduced reaction time ${ }^{12,13}$. It is more economical to synthesize materials using microwave heating as compared to conventional methods such as mechanical milling, carbothermal reduction and laser synthesis since microwave heating is well known for low energy consumption, shorter reaction time and very low impurities such as oxygen and metals reside in the end products after synthesis ${ }^{14-16}$. The characteristic of microwave heating is attributed to the fact that microwave is a form of electromagnetic energy with a frequency range from $300 \mathrm{MHz}$ to $300 \mathrm{GHz}$ and microwave can couple with certain materials which have excellent dielectric properties such as carbon and it can be absorbed into these materials volumetrically which then transformed to heat from the inside of materials ${ }^{17,18}$. Conventional heating method involves the transfer of heat between objects by the mechanisms of conduction, convection and radiation ${ }^{19}$. Heat loss to surrounding and irregular heat transfer between the heat source and material often becomes the issue of conventional heating and causes low heating rate and high energy consumption. Li et. $\mathrm{al}^{20}$ have reported that by using microwave heating, one can successfully synthesize nanostructured $\beta$-SiC in argon atmosphere. Compared to conventional heating, microwave heating was proven to be an efficient approach to synthesize $\mathrm{SiC}$ in terms of low energy consumption and time saving. Carbon materials such as MWCNTs are well known as good microwaves absorber $^{21}$. It is expected that by microwaves heating the blend of MWCNTs and $\mathrm{SiO}_{2}$, SiCNTs can be synthesized from the reaction of MWCNTs and $\mathrm{SiO}_{2}$. To date, no study was reported on the synthesis of SiCNTs by microwaves heating of blends of MWCNTs and $\mathrm{SiO}_{2}$.

In the previous study, several researchers have investigated the effect of ratio of raw material on the synthesis of $\mathrm{SiC}$ nano-material ${ }^{22,23}$. For example, Ding et $\mathrm{al}^{24}$ in their study synthesis of $\mathrm{SiC}$ nanowires by using molten salt synthesis (MSS) method at temperature of $1400^{\circ} \mathrm{C}$ indicates that ratio of raw materials is an important factor to synthesize SiC nanowires and they revealed that intensity of $\beta$-SiC peaks of ratio 1:3 was higher compared to $\mathrm{Si}$ and salts containing carbon of ratio 1:1, 1:2 and 1:4 which suggested that formation of $\mathrm{SiC}$ nanowires was highest when $\mathrm{Si}$ and salts containing carbon of ratio 1:3 was used. Besides that, $\mathrm{Bi}$ et $\mathrm{al}^{25}$ reported the synthesis of the $\mathrm{SiC} / \mathrm{CNT}$ s hetero-structures from the solgel mixture containing the mixture of MWCNTs and silica gel in various ratios by using tube furnace at temperature of $1400^{\circ} \mathrm{C}$ for 60 minutes. They found out that increase of molar ratio of MWCNTs in mixture caused high residual of MWCNTs and revealed that almost all reactant of silica gel and MWCNTs in the ratio of 1:3 was consumed and formed $\mathrm{SiC} / \mathrm{CNTs}$ hetero-structures. Therefore, these studies indicate that ratio of raw materials has significant effect in the purity and quality of the synthesized SiCNTs.

$\mathrm{Bi}$ et $\mathrm{al}^{25}$ and Quah et $\mathrm{al}^{26}$ also studied and reported the effect of different ratios of the $\mathrm{SiO}_{2}$ particles and CNTs. However, in this article we studied the effect of different ratios of $\mathrm{SiO}_{2}$ particles and MWCNTs with a different synthesis approach which is by using microwave heating rather than conventional heating method used by Bi et al and Quah et al. Thus, in this paper, the effect of molar ratio of MWCNTs and $\mathrm{SiO}_{2}$ on the synthesis of SiCNTs was studied and reported, considering its importance on the properties of the prepared materials. We revealed the morphology, composition, optical and quality of SiCNTs that were synthesized by microwave heating of the blend of $\mathrm{SiO}_{2}$ and MWCNTs in different ratios. In order to identify the effect of molar ratio of $\mathrm{SiO}_{2}$ and MWCNT for the synthesis of SiCNTs, the as-synthesized SiCNTs were characterized using X-ray diffraction, field emission scanning electron microscopy, transmission electron microscopy, photoluminescence spectroscopy, fourier transform infrared spectroscopy, and thermal gravimetric analysis.

\section{Experimental}

In this study, the materials used were multi-walled carbon nanotubes (MWCNTs) and silicon dioxide $\left(\mathrm{SiO}_{2}\right)$, which were purchased from Sigma Aldrich. $\mathrm{SiO}_{2}$ (particles size of $44 \mu \mathrm{m}$ and purity $99 \%$ ) was mixed properly with MWCNTs (diameter range from 10 to $70 \mathrm{~nm}$ ) in the ratio of $1: 1,1: 3$, 1:5 and 1:7 using ethanol as a liquid medium in ultrasonic bath for 2 hours. After the mixing process, the mixtures were dried using hot plate until ethanol was completely evaporated and the mixtures were pressed into solid pellet form with a thickness of $3 \mathrm{~mm}$ to ease the sample handling during transferring to and out of microwave cavity and also to minimize the loss of $\mathrm{SiO}$ gas produced to surroundings.

$2.45 \mathrm{GHz}$ multi-mode cavity microwave furnace model HAmiLab-V3 from SYNOTHERM was used to conduct microwave heating. Figure 1 shows the arrangement of alumina crucible in microwave cavity which filled with silica sand, graphite and $\mathrm{SiC}$ susceptor and blends of different molar ratios $(1: 1,1: 3,1: 5$ and 1:7) were placed at the center of alumina crucible. Silica sand is a good heat insulator and it can reduce the heat loss to surroundings while $\mathrm{SiC}$ susceptor has ability to absorb the microwave energy at low temperature and acts as the external heat source which helps to achieve high heating rate. Meanwhile, graphite can absorb the microwave energy and produced heat energy which then transferred to samples to increase heating rate. The cavity was vacuumed and pure argon gas atmosphere was introduced into microwave cavity during the synthesis. 
Heating rate of $30^{\circ} \mathrm{C} / \mathrm{min}$ were used during microwave heating to reach the required temperature at $1400^{\circ} \mathrm{C}$ and maintained for 40 minutes. The power of microwave used in this study was within the range of 0.3 to $2.85 \mathrm{~kW}$ and the power was adjusted automatically by the microwave furnace since automatic mode was used. Therefore, the power of microwave energy fluctuated during the synthesis so that the preset temperature and heating rate can be obtained. The specimens were cooled in the microwave cavity to room temperature.

\section{PYROMETER MEASUREMENT}

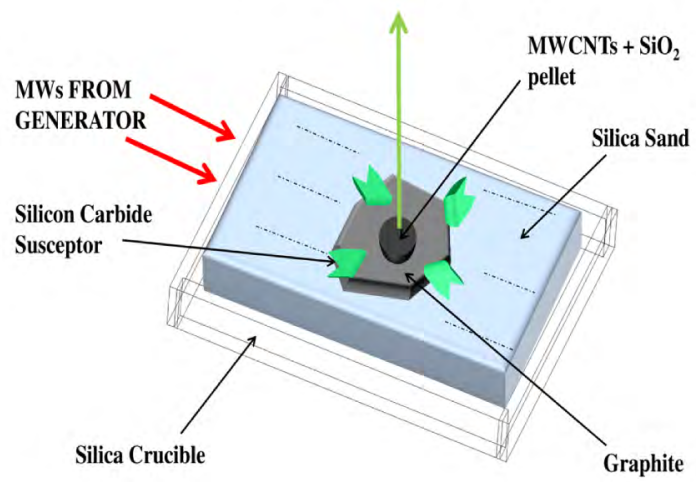

Figure 1. Schematic diagram of setup inside microwave cavity

The specimens were characterized using X-ray diffraction (XRD), field emission scanning electron microscopy (FESEM), transmission electron microscopy (TEM), photoluminescence spectroscopy (PL), fourier transform infrared spectroscopy (FTIR) and thermal gravimetric analysis (TGA). XRD Siemens Diffractometer Model D-5000 using $\mathrm{Cu} \mathrm{K} \alpha$ radiation source in $\theta / 2 \theta$ mode was used to investigate the crystalline phase present in the specimens. Measurements were made with fast duration scan (1s) and small step size $\left(0.02^{\circ}\right)$. Meanwhile, the morphologies of specimens were observed by using FESEM model Nova Nano 450 at magnification $200 \mathrm{~K}$ and accelerating voltage of $5 \mathrm{kV}$. Tubular structure of SiCNTs was confirmed using transmission electron microscopy model Philips Tecnai F20 TEM. Optical properties of SiCNTs were identified by using the photoluminescence spectroscopy (PL FL3-11 J81040) with xenon lamp of 400 watt and excitation wavelength at $265 \mathrm{~nm}$ and photoluminescence baseline subtraction was conducted by using OriginPro 8 by using method of auto-create a modifiable baseline with baseline algorithm of end weighted. Reference baseline then was subtracted and the graph was plotted. Fourier transform infrared (FTIR MAGNA550 kBr) spectroscopy was used to scan the samples from $500-4000 \mathrm{~cm}^{-1}$ with a spectrum resolution of $4 \mathrm{~cm}^{-1}$. Thermal stability of SiCNTs was evaluated using Perkin-Elmer Pyris 6 TGA analyzer. Samples about 10 $\mathrm{mg}$ weight were heated from 30 to $1300^{\circ} \mathrm{C}$ with a heating rate of $10^{\circ} \mathrm{C} / \mathrm{min}$ in atmospheric air in order to investigate the thermal stability of the synthesized SiCNTs. Raman spectroscopy was conducted by using Raman Spectrometer model Renishaw InVia Raman Microscope with excitation of $633 \mathrm{~nm} \mathrm{HeNe}$ laser and spectral range was taken from 650 to $1800 \mathrm{~cm}^{-1}$.

\section{Results and Discussion}

\subsection{X-Ray diffraction (XRD) patterns}

Figure 2 shows the XRD patterns of $\mathrm{SiO}_{2}$ particles and MWCNTs. Two broad peaks centered at $23^{\circ}$ and $43^{\circ}$ in Figure 2 a) shows that MWCNTs are amorphous while many sharp peaks in XRD pattern of $\mathrm{SiO}_{2}$ particles in Figure $2 \mathrm{~b}$ ) revealed that $\mathrm{SiO}_{2}$ particles are crystalline. Meanwhile, Figure 3 shows XRD pattern of SiCNTs synthesized from blends of $\mathrm{SiO}_{2}$ and MWCNTs in the ratio of 1:1, 1:3, 1:5 and 1:7. It can be seen in Figure 3 (a)-(d) that the characteristic peaks of $\beta$-SiC centered at $2 \theta=36.2^{\circ}, 43^{\circ}, 60^{\circ}$ and $73.4^{\circ}$, which are associated with (111), (200), (220) and (311) planes of $\beta$-SiC (JCPDS Card No: 29-1129), respectively were observed in XRD patterns of all specimens synthesized from the blend of $\mathrm{SiO}_{2}$ and MWCNTs in the ratio of 1:1, 1:3, 1:5 and 1:7, respectively. This indicated that SiCNT was successfully synthesized from the blend of $\mathrm{SiO}_{2}$ and MWCNTs regardless of the ratio of MWCNTs and $\mathrm{SiO}_{2}$. It is worth mentioning that in XRD pattern of SiCNTs synthesized from the blend of $\mathrm{SiO}_{2}$ and MWCNTs in the ratio of 1:1 in Figure 3 (a), there is a peak corresponding to the residual of unreacted $\mathrm{SiO}_{2}$ at $2 \theta=23^{\circ}$ associated with (100) planes of $\mathrm{SiO}_{2}$ particles. Very small XRD peak corresponded to residual of unreacted MWCNTs were observed at $2 \theta=27.3^{\circ}$ associated with (002) planes of carbon. This shows that amount of MWCNTs in the blend to react with $\mathrm{SiO}_{2}$ was not sufficient when $\mathrm{SiO}_{2}$ and MWCNTs were in the ratio of 1:1. Thus, unreacted $\mathrm{SiO}_{2}$ was detected with very small residual MWCNTs observed and only small amounts of SiCNTs were produced.

For SiCNTs synthesized from the blend of $\mathrm{SiO}_{2}$ and MWCNTs in the ratio of 1:3, XRD peaks corresponding to $\beta$-SiC can be observed from the XRD pattern as shown in Figure 3 (b). This indicated that the ratio 1:3 of $\mathrm{SiO}_{2}$ to MWCNTs is the suitable ratio to synthesize SiCNTs, because only very small residue of unreacted $\mathrm{SiO}_{2}$ and MWCNTs was observed in the XRD pattern. Meanwhile, XRD pattern for SiCNTs synthesized from the blend of $\mathrm{SiO}_{2}$ and MWCNTs in the ratio of 1:5 and 1:7 (Figure 3 (c) and (d)) show residual of unreacted MWCNTs at $2 \theta=27^{\circ}$ associated with (002) planes of carbon. These residual of MWCNTs was amorphous as indicated in XRD patterns in Figure 3 (c) and (d) which show broad peak of carbon peak. It is postulated that the reaction was not completed because there was no sufficient $\mathrm{SiO}_{2}$ to react with MWCNTs and thus significant amount of MWCNTs were not converted to SiCNTs. The result is consistent with the chemical reaction between the $\mathrm{SiO}_{2}$ and 


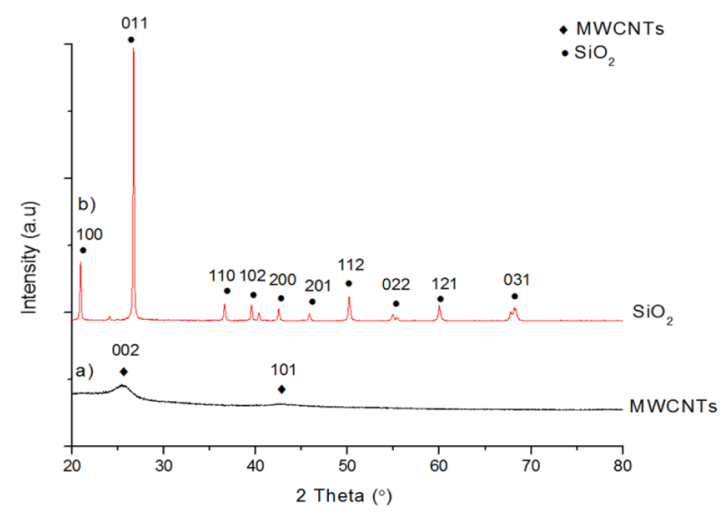

Figure 2. XRD pattern of a) $\mathrm{SiO}_{2}$ particles and b) MWCNTs.

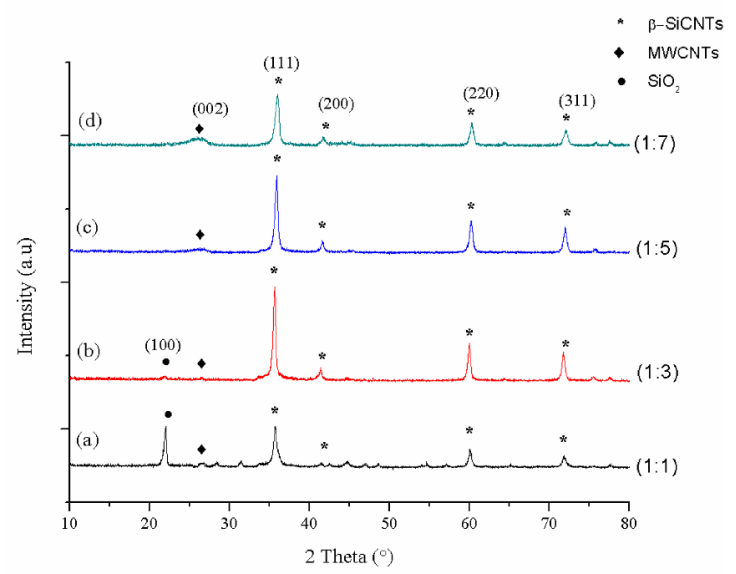

Figure 3. XRD patterns of SiCNTs synthesized from blend of $\mathrm{SiO}_{2}$ and MWCNTs in the ratio of a) $1: 1$; b) $1: 3$; c) $1: 5$ and d) $1: 7$.

MWCNTs as shown by Equation (3.1) below which suggested that synthesized SiCNTs from ratio 1:3 gives highest yield conversion of $\mathrm{SiO}_{2}$ particles and MWCNTs to SiCNTs ${ }^{25}$.

$$
\mathrm{SiO}_{2}(s)+3 \mathrm{C}(\mathrm{s}) \rightarrow \mathrm{SiC}(\mathrm{s})+2 \mathrm{CO}(\mathrm{g})
$$

Similar observation was reported by Ding et $\mathrm{al}^{22}$ in his research to synthesize $\mathrm{SiC}$ nanowires from graphite and Si powder by molten salt synthesis method, in which they concluded that the ratio of Si powder to carbon (graphite) was crucial in order to synthesize $\mathrm{SiC}$ nanowires without any excess of unreacted graphite and Si powder and they revealed that the mixture of Si powder and graphite in the ratio of $1: 3$ was most favorable to synthesize $\mathrm{SiC}$ nanowires. $\mathrm{Bi}$ et a ${ }^{25}$ also confirmed that the ratio $1: 3$ of $\mathrm{SiO}_{2}$ to MWCNTs can be used to synthesize SiCNTs by using the tube furnace with only small amounts of MWCNTs left as residue compared to other ratio as shown in XRD pattern.

\subsection{Field emission scanning electron microscopy (FESEM) images}

FESEM images of $\mathrm{SiO}_{2}$ particles, MWCNTs and SiCNTs synthesized from the blend of $\mathrm{SiO}_{2}$ and MWCNTs with a ratio ranged from 1:1, 1:3, 1:5 and 1:7 were shown in Figure 4. It can be observed that $\mathrm{SiO}_{2}$ particles were agglomerates of smaller particles which formed larger particles as shown in Figure 4 (a) while Figure 4 (b) shows the MWCNTs have smooth surface with diameter range from 11 to $70 \mathrm{~nm}$. Meanwhile, it can be seen in Figure 4 (c) that for SiCNTs synthesized from the blend of $\mathrm{SiO}_{2}$ and MWCNTs of ratio 1:1, there is unreacted $\mathrm{SiO}_{2}$ (pointed out by red circle) due to the amount of MWCNTs available to react with $\mathrm{SiO}_{2}$ was insufficient when $\mathrm{SiO}_{2}$ and MWCNTs were in the ratio of 1:1. FESEM images in Figure 4 (d) show that SiCNTs synthesized from the blend of $\mathrm{SiO}_{2}$ and MWCNTs in the ratio of $1: 3$ is the suitable ratio for the synthesis of SiCNTs as high yield conversion of $\mathrm{SiO}_{2}$ particles and MWCNTs to SiCNTs was achieved as illustrated in FESEM images.

Meanwhile, FESEM images of SiCNTs synthesized from the blend of $\mathrm{SiO}_{2}$ and MWCNTs in the ratio of 1:5 and 1:7 as shown in Figure 4 (e) and (f) revealed that there were residuals of unreacted MWCNTs (pointed out by blue circle). This might be due to the fact that $\mathrm{SiO}_{2}$ was insufficient to react with MWCNTs and thus some MWCNTs were not converted to SiCNTs. These results from Figure 4 are in good agreement with the XRD pattern of the SiCNTs in Figure 3 in which high yield conversion of $\mathrm{SiO}_{2}$ and MWCNTs to $\beta$-SiCNTs was achieved, when the blend of $\mathrm{SiO}_{2}$ and MWCNTs was in the ratio of $1: 3$ with very small residual of $\mathrm{SiO}_{2}$ particles was detected. However, no $\mathrm{SiO}_{2}$ particle was observed in FESEM image of SiCNTs synthesized from the blend of $\mathrm{SiO}_{2}$ and MWCNTs in the ratio of $1: 3$ and this may due to the very small amount of residue of $\mathrm{SiO}_{2}$ particles which caused difficulty to detect $\mathrm{SiO}_{2}$ particles in FESEM image. It can be observed also from FESEM images of SiCNTs in Figure 3 (c) - (f) that diameter of the SiCNTs produced in this study was in the range of 11-71 nm while diameter of MWCNTs in Figure 3 (b) was in the range of 11-70 nm. This shows that there is no obvious change in the diameter of nanotube after MWCNTs were converted to SiCNTs.

\subsection{Transmission electron microscopy (TEM) images}

TEM images of MWCNTs and SiCNTs synthesized from blend of $\mathrm{SiO}_{2}$ and MWCNTs in the ratio of 1:3 were showed in Figure 5. Figure 5 (a) shows that the tubular structure of MWCNTs and it can be observed that MWCNTs has inter-planar spacing of $0.34 \mathrm{~nm}$ as reported by others ${ }^{27}$. TEM images in Figure 5 (b) showed that the SiCNTs has rough surface which may due to the reaction of $\mathrm{SiO}$ gas with carbon atoms at the surface of MWCNTs, resulted in the formation of defects as some of carbon atoms formed $\mathrm{CO}$ gas as explained later. Figure 5 (b) reveals that the SiCNTs has inter-planar spacing of $0.25 \mathrm{~nm}$. This showed the SiCNTs was successfully formed after the synthesis and the tubular structure of MWCNTs was conserved. Similar result has been reported by Dai et $\mathrm{a}^{28}$ in which they found 

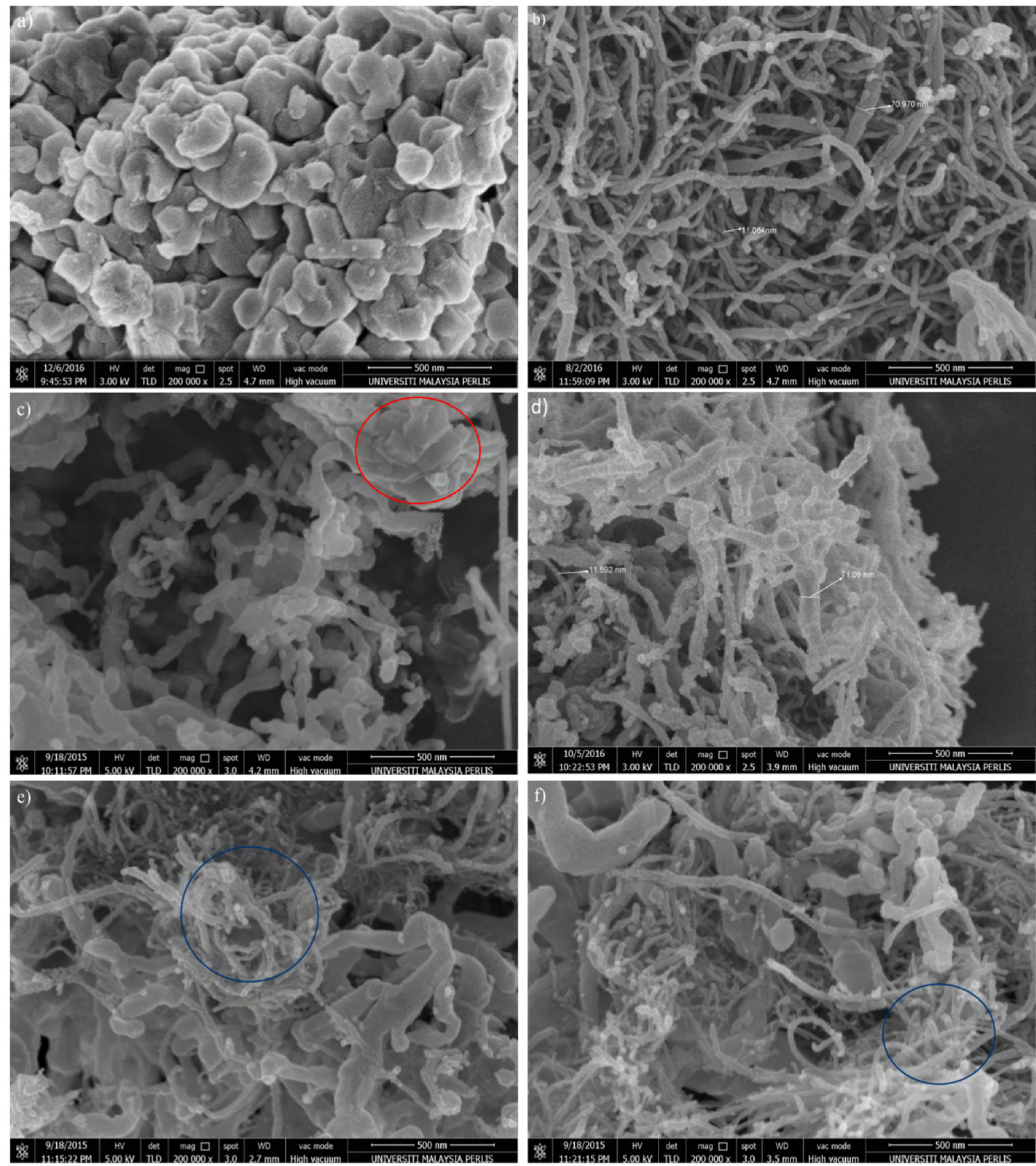

Figure 4. FESEM images of a) $\mathrm{SiO}_{2}$ particles, b) MWCNTs and SiCNTs synthesized from blend of $\mathrm{SiO}_{2}$ and MWCNTs in the ratio of c) $1: 1$;) $1: 3$; e) 1:5 and f) 1:7. Red circle: Silicon dioxide particle $\left(\mathrm{SiO}_{2}\right)$, Blue circle: Multi-walled carbon nanotubes (MWCNTs).

that inter-planar spacing of $\mathrm{SiC}$ nanowire was observed to be $0.25 \mathrm{~nm}$. It can be that diameter of SiCNTs in TEM image was in $13 \mathrm{~nm}$ which is in good consistence with the diameter of SiCNTs in the range of 11-71 nm as observed in FESEM image.

\subsection{Photoluminescence spectroscopy (PL) spectra}

PL spectra of SiCNTs synthesized from the blend of $\mathrm{SiO}_{2}$ and MWCNTs in the ratio of 1:1, 1:3, 1:5 and 1:7 are shown in Figure 6. Samples were excited by ultraviolet fluorescent light at $265 \mathrm{~nm}$ from a Xe lamp at room temperature. It can be observed that all the PL spectra of SiCNTs synthesized from the blend of $\mathrm{SiO}_{2}$ and MWCNTs in the ratio of 1:1, 1:3, 1:5 and 1:7 respectively have a strong PL peak of $\beta$-SiCNTs at wavelength of $465 \mathrm{~nm}$ corresponding to band gap of $2.67 \mathrm{eV}$. Compared to band gap of bulk $3 \mathrm{C}-\mathrm{SiC}$ of $2.39 \mathrm{eV}^{29}$, the PL peaks of SiCNTs are considerably blue shifted. It is believed that this is due to quantum confinement effect. The results were in good agreement with the value reported by Chen et $\mathrm{al}^{30}$, which reported that silicon carbide nanowire exhibits a strong and sharp emission at $470 \mathrm{~nm}$ and corresponded to band gaps of $2.64 \mathrm{eV}$. Nazarudin et $\mathrm{al}^{31}$ also concluded that 

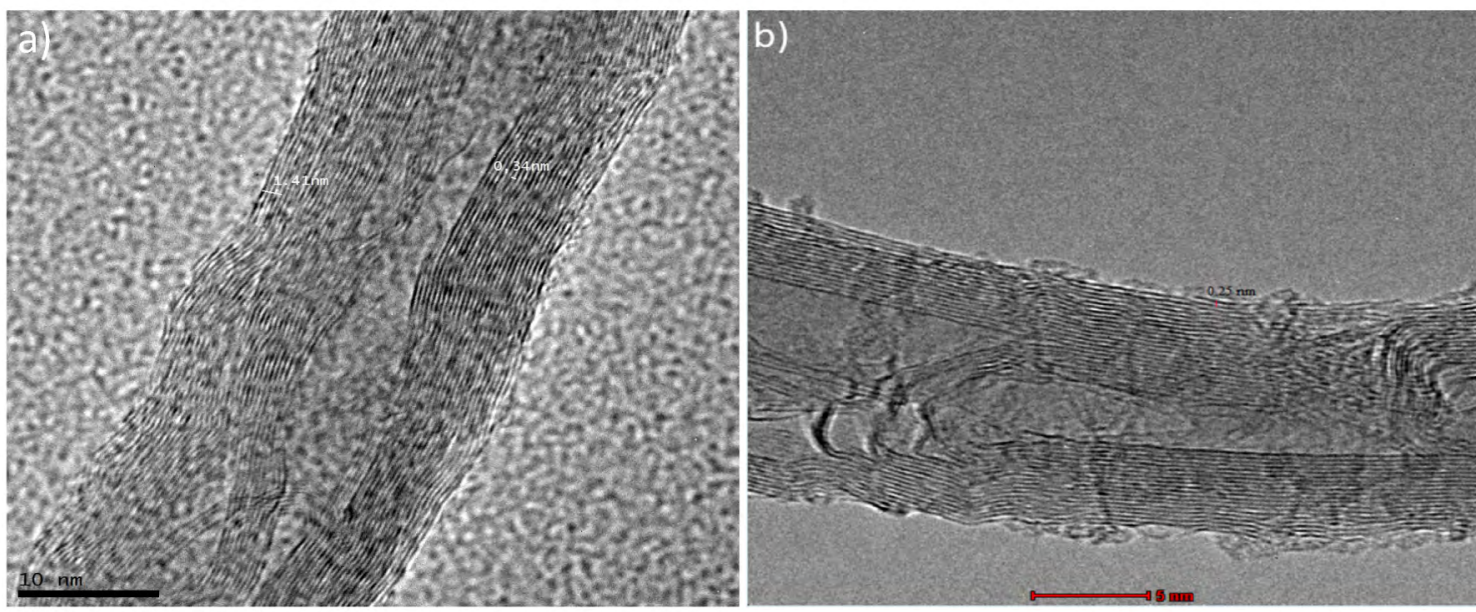

Figure 5. TEM images of a) SiCNTs synthesized from blend of $\mathrm{SiO}_{2}$ and MWCNTs in the ratio of 1:3 and b) HRTEM images of SiCNTs.

the PL of the SiC nano-crystalizes is strongly dependent on quantum confinement effects attributed to the size of the nano-crystallites embedded in the nanowires.

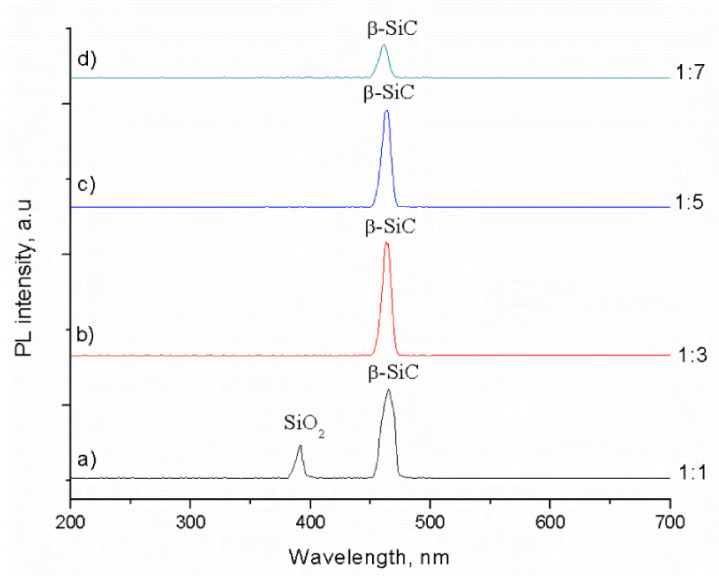

Figure 6. PL spectrum of SiCNTs synthesized from blend of $\mathrm{SiO}_{2}$ and MWCNTs in the ratio of a) $1: 1$; b) $1: 3$; c) $1: 5$ and d) $1: 7$.

In Figure 6 (a), PL spectrum of SiCNTs synthesized from the blend of $\mathrm{SiO}_{2}$ and MWCNTs in the ratio of 1:1 shows the presence of strong PL peak attributed to oxygen discrepancy in $\mathrm{SiO}_{2}$ at $387 \mathrm{~nm}$ and corresponded to band gaps of $3.2 \mathrm{eV}$. The presence of this peak is in good consistence with the XRD result of SiCNTs synthesized from the blend of $\mathrm{SiO}_{2}$ and MWCNTs in the ratio of 1:1 (Figure 3 (a)), which shows the presence of XRD peak corresponded to $\mathrm{SiO}_{2}$. This is due to the presence of $\mathrm{SiO}_{2}$ which was remained unreacted because of insufficient MWCNTs in the mixture. Similar result was also reported by Chiu and $\mathrm{Li}^{32}$, they reported that there was an emission peak centered at $390 \mathrm{~nm}$ which was attributed to the oxygen discrepancy in $\mathrm{SiO}_{2}$ particles and thus indicated the presence of $\mathrm{SiO}_{2}$ particles after the synthesis of SiC.
PL spectrum of SiCNTs synthesized from the blend of $\mathrm{SiO}_{2}$ and MWCNTs in the ratio of 1:3 (Figure 6 (b)) consisted of single peak corresponding to $\beta$-SiCNTs at a wavelength of $465 \mathrm{~nm}$ with band gaps of $2.67 \mathrm{eV}$. This revealed that SiCNTs synthesized from the blend of $\mathrm{SiO}_{2}$ and MWCNTs in the ratio of $1: 3$ consisted only $\beta$-SiCNTs. However, XRD pattern in Figure 3 (b) shows the presence of very small peak of $\mathrm{SiO}_{2}$ particles but PL peak corresponded to $\mathrm{SiO}_{2}$ particles was not observed in Figure 6 (b). This may due to the amount of $\mathrm{SiO}_{2}$ particles was too small to be detected by PL. Meanwhile, for the PL spectra of SiCNTs synthesized from the blends of $\mathrm{SiO}_{2}$ and MWCNTs in the ratio of 1:5 and 1:7 in Figure 6 (c) and (d), it can be seen that only peak corresponding to $\beta$-SiCNTs were observed at wavelength of $465 \mathrm{~nm}$ although significant amount of MWCNTs remained unreacted and was detected in XRD patterns. No PL peak corresponded to MWCNTs was observed from the PL spectra of SiCNTs synthesized from the blend of $\mathrm{SiO}_{2}$ and MWCNTs in the ratio of 1:5 and 1:7. This was due to the quenching effect of the MWCNTs where the electrons are trapped in MWCNTs and thus decreases the PL intensity. MWCNTs are well known as good electron acceptors ${ }^{33}$ and thus can act as electron storage to trap electrons. Several researchers also have reported the similar result in which they reported no PL peak of MWCNTs was observed ${ }^{34,35,36}$. Besides that, it was also observed that the intensity of PL peak corresponded to $\beta-\mathrm{SiC}$ of SiCNTs in the ratio of 1:7 was lower than SiCNTs in the ratio of 1:5. This was due to the reduced electron-hole recombination rate for SiCNTs in the ratio of 1:7 comparing to the SiCNTs in the ratio of 1:5. Similar result was also reported by Gui et $\mathrm{al}^{37}$ in their study of $\mathrm{TiO}_{2} / \mathrm{MWCNTs}$ and roles of MWCNTs on surface chemistry, optical properties and reactivity in $\mathrm{CO}_{2}$ photoreduction. They reported that increase of the MWCNTs loading in $\mathrm{TiO}_{2} / \mathrm{MWCNTs}$ caused great reduction of the PL 
intensity of $\mathrm{TiO}_{2}$ due to the inhibition of the electron-hole recombination in $\mathrm{TiO}_{2}$.

\subsection{Fourier transform infrared (FTIR) spectra}

To analyze the chemical bonding of the SiCNTs synthesized from the blend of $\mathrm{SiO}_{2}$ and MWCNTs in the ratio of 1:1, 1:3, 1:5 and 1:7, FTIR spectroscopy was used and the FTIR spectra of the SiCNTs are shown in Figure 7. FTIR peak corresponded to Si-C stretching bond was present at $1000-800 \mathrm{~cm}^{-1}$ in all FTIR spectra of SiCNTs synthesized from the blend of $\mathrm{SiO}_{2}$ and MWCNTs in the ratio of 1:1, 1:3, 1:5 and 1:7. From Figure 7 (a), it can be observed that SiCNTs synthesized from the blend of $\mathrm{SiO}_{2}$ and MWCNTs in the ratio of 1:1 has FTIR peak corresponded to stretching bond of Si-O bonding group at $1110 \mathrm{~cm}^{-138}$. These indicated that some of $\mathrm{SiO}_{2}$ particles were not reacted with MWCNTs during the heating process.

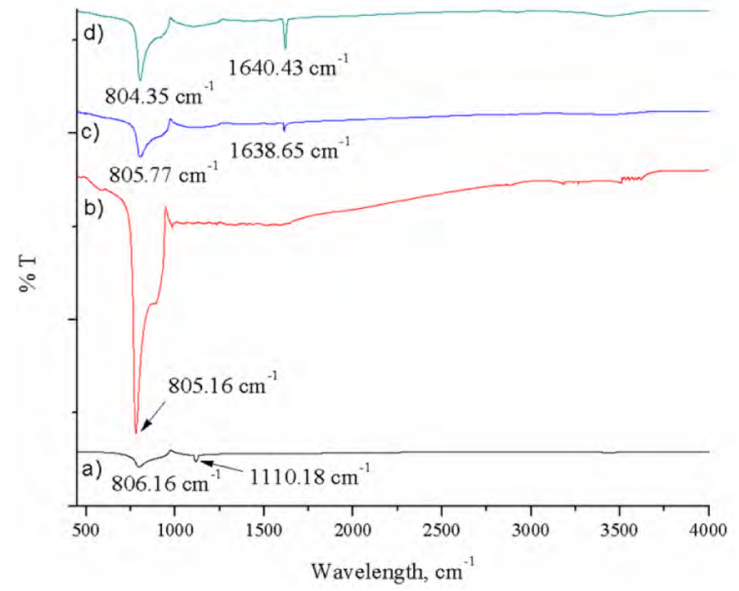

Figure 7. FTIR spectrum of SiCNTs synthesized from blend of $\mathrm{SiO}_{2}$ and MWCNTs in the ratio of a) 1:1; b) 1:3; c) 1:5 and d) 1:7.

Meanwhile, SiCNTs synthesized from the blend of $\mathrm{SiO}_{2}$ and MWCNTs in the ratio of 1:3 in Figure 7 (b) shows FTIR absorption band centered at $806 \mathrm{~cm}^{-1}$ which corresponded to stretching vibration of $\mathrm{Si}-\mathrm{C}$ bonds. This result is in good consistence with the XRD result of SiCNTs synthesized from the ratio of 1:3 (Figure 2 (b)) which shows high yield conversion of $\mathrm{SiO}_{2}$ particles and MWCNTs to $\beta$-SiCNTs when blend of ratio 1:3 of $\mathrm{SiO}_{2}$ particles and MWCNTs was used. Chen et $\mathrm{al}^{39}$ revealed similar result where strong FTIR peak centered at $820 \mathrm{~cm}^{-1}$ corresponded to transverse optical photon vibration mode of Si-C bond was observed from the FTIR spectra of synthesized $3 \mathrm{C}$-SiC nanowires.

FTIR spectra of SiCNTs synthesized from the blend of $\mathrm{SiO}_{2}$ and MWCNTs in the ratio of 1:5 and 1:7 (Figure 7 (c) and (d)) revealed the presence of FTIR peaks corresponded to $\mathrm{C}=\mathrm{C}$ stretching bonds centered at $1640 \mathrm{~cm}^{-140}$. The presence of these peaks indicated that some of the MWCNTs were not converted to SiCNTs and this may due to the insufficient amount of $\mathrm{SiO}_{2}$ particles to react with MWCNTs.

\subsection{Thermal gravimetric analysis (TGA)}

Thermal stability of SiCNTs synthesized from the blend of $\mathrm{SiO}_{2}$ and MWCNTs in the ratio of 1:1, 1:3, 1:5 and 1:7 was evaluated by using thermal gravimetric analysis. The TGA curves are shown in Figure 8. It can be observed from all TGA curves that no weight loss took place when $\mathrm{SiC}$ was heated up to $600^{\circ} \mathrm{C}$. The decomposition only started to occur when the temperature was higher than $600{ }^{\circ} \mathrm{C}$ which was attributed to the oxidation of MWCNTs. Giorcelli et a ${ }^{41}$ reported similar observation in which $\mathrm{SiC}$ hollow cylinder synthesized by using MWCNTs has decomposed at $600^{\circ} \mathrm{C}$ in their TGA study.

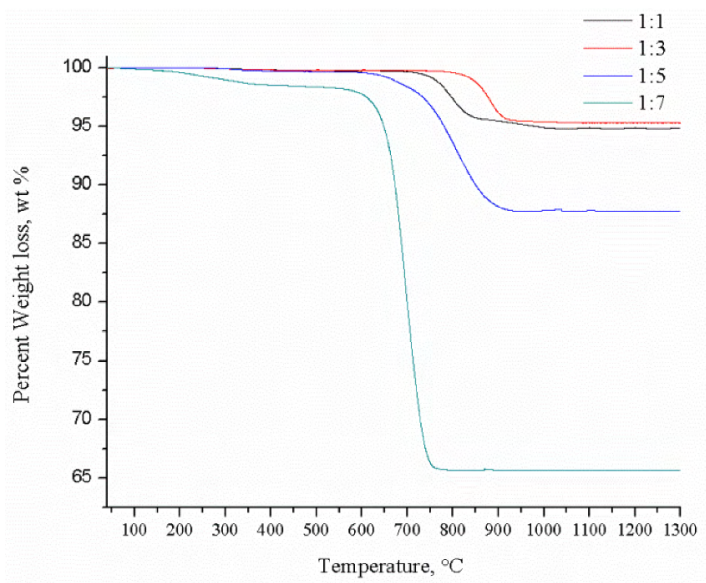

Figure 8. TGA analysis of SiCNTs synthesized from blend of $\mathrm{SiO}_{2}$ and MWCNTs in the ratio of $1: 1 ; 1: 3 ; 1: 5$ and $1: 7$.

It can be observed that SiCNTs synthesized from the blend of $\mathrm{SiO}_{2}$ and MWCNTs in the ratio of 1:1 has shown weight loss of $5 \%$ and started at $700{ }^{\circ} \mathrm{C}$. It is believed that this weight loss of $5 \%$ was due to the decomposition of the residual MWCNTs and this result also shows good agreement with XRD pattern of SiCNTs in Figure 3 (a) in which very small XRD peak corresponded to carbon was observed and indicates the presence of small amount of residual MWCNTs. Li et al. ${ }^{42}$ also reported similar result in which they reported that decomposition of the MWCNTs occurred at temperature of $700^{\circ} \mathrm{C}$ to $800^{\circ} \mathrm{C}$ in $\mathrm{SiC} / \mathrm{MWCNTs}$ and revealed the thermal stability of CNTs was enhanced in $\mathrm{SiC} / \mathrm{CNTs}$ which led to higher resistance of MWCNTs toward oxidation.

Meanwhile, from Figure 8, TGA curved shows the SiCNTs synthesized from the blend of $\mathrm{SiO}_{2}$ and MWCNTs in the ratio of 1:3, 1:5 and 1:7 has weight loss of $4 \%, 12 \%$ and $35 \%$, respectively. This weight loss was attributed to the oxidation of residual MWCNTs. This result also shown a good agreement with XRD patterns of SiCNTs in Figure 3 which show there are very small amount of residual MWCNTs for ratio 1:3 while ratio 1:5 and 1:7 show significant amount of residual MWCNTs. Besides that, the amount of SiCNTs produced was reduced as the carbon in the blends increased from ratio of 1:3, 1:5 to 1:7. SiCNTs can help to 
protect MWCNTs from further oxidation by increasing the decomposition temperature of MWCNTs. As ratio 1:3 has produced high yield of SiCNTs as shown in XRD pattern in Figure 3, SiCNTs can effectively protect MWCNTs from decomposition. However, large weight loss of ratio 1:5 and 1:7 was due to the oxidation of MWCNTs since only small amount of SiCNTs was produced. Besides, the starting temperature for the decomposition was reduced to $650{ }^{\circ} \mathrm{C}$ and $600{ }^{\circ} \mathrm{C}$ for ratio $1: 5$ and $1: 7$, respectively due to the smaller amount of SiCNTs in the samples which cannot effectively improve the thermal stability of MWCNTs. Similar result was reported by $\mathrm{Li}$ et al. ${ }^{42}$ in which they reported in the thermal gravimetric analysis of pure MWCNTs, the decomposition started at $550^{\circ} \mathrm{C}$ while for SiC/MWCNTs, decomposition of MWCNTs started at $700^{\circ} \mathrm{C}$, denoting the presence of SiCNTs can enhance the thermal stability of MWCNTs.

\subsection{Raman spectroscopy}

SiCNTs synthesized from blend of $\mathrm{SiO}_{2}$ particles and MWCNTs in the ratio of $1: 3$ shows peaks corresponded to $\beta$-SiC at $797 \mathrm{~cm}^{-1}$ and $970 \mathrm{~cm}^{-1}$, respectively in Raman spectrum in Figure 9. This peaks confirmed the presence of SiCNTs. Giorcelli et $\mathrm{al}^{41}$ also showed similar result where peaks corresponded to transversal optical phonon (TO) and longitudinal optical phonon (LO) of 3C-SiC were observed at $797 \mathrm{~cm}^{-1}$ and $968 \mathrm{~cm}^{-1}$. Besides that, it can be observed that there are peaks corresponded to the CNTs at $1350 \mathrm{~cm}^{-1}$ and $1565 \mathrm{~cm}^{-1}$ which revealed the presence of small amount of residual of MWCNTs in SiCNTs. Pan et $\mathrm{al}^{43}$ also reported similar Raman peaks which corresponded to the vibrations of carbon atoms with dangling bonds at $1346 \mathrm{~cm}^{-1}$ and 1568 $\mathrm{cm}^{-1}$ and thus revealed the presence of CNTs in SiC-CNTs composite. This result also show good agreement with XRD pattern of SiCNTs in ratio of 1:3 from Figure $3(\mathrm{~b})$ which shows the presence of very small amount of MWCNTs.

\subsection{Growth mechanism of silicon carbide nanotubes (SiCNTS)}

Several mechanisms for the growth of one dimensional nanostructure have been proposed such as vapor-liquid-solid $(\mathrm{VLS})^{44}$, vapor-solid (VS) ${ }^{45}$ and solid-liquid-solid (SLS) ${ }^{46}$ mechanisms. In this study, mechanism of vapor-solid (VS) was suggested to explain the synthesis of SiCNTs from the blend of $\mathrm{SiO}_{2}$ and MWCNTs at $1400{ }^{\circ} \mathrm{C}$ with heating rate of $30{ }^{\circ} \mathrm{C} / \mathrm{min}$ and maintained for 40 minute. Synthesis by VS mechanism has advantages where it does not need catalyst for the formation of 1D morphology and thus no purification of the product is required. However, comparing to VLS mechanism, generally 1D material was not uniform and the diameter can vary over a wider range. The formation of SiCNTs involved three stages according to VS mechanism which are microwaves heating of blend of $\mathrm{SiO}_{2}$ and MWCNTs, vaporization of $\mathrm{SiO}_{2}$ to $\mathrm{SiO}$ gas and conversion of MWCNTs to SiCNTs.

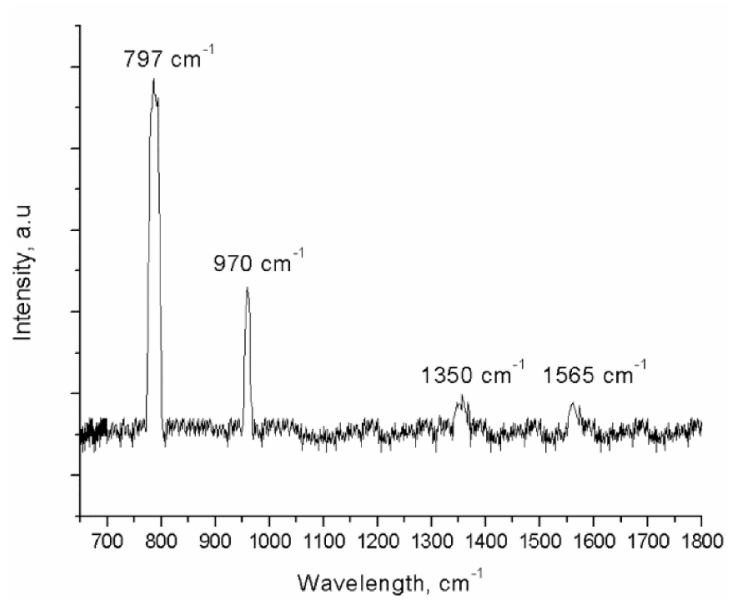

Figure 9. Raman spectrum of SiCNTs synthesized from blend of $\mathrm{SiO}_{2}$ and MWCNTs in the ratio of $1: 3$.

In the first stage as shown in Figure 10 (a), the blend of $\mathrm{SiO}_{2}$ and MWCNTs was exposed to the microwave heating such that the temperature reached $1400{ }^{\circ} \mathrm{C}$ with heating rate of $30^{\circ} \mathrm{C} / \mathrm{min}$ and maintained for 40 minutes. When exposing to microwave irradiation, carbon materials such as MWCNTs were able to absorb the microwave irradiation as indicated by red arrows (Figure 10 (a)). Carbon materials can be heated by microwaves because of delocalized $\pi$ electrons, which are free to move within the orbital structure of carbon. As the carbon continue to absorb the microwave energy, the kinetic energy of delocalized $\pi$ electron increased and thus each carbon atom started to vibrate and move ${ }^{47}$. These actions caused the heat to generate volumetrically after absorbing the microwave energy and thus temperature of carbon materials increased. Meanwhile, $\mathrm{SiO}_{2}$ is a microwave reflector, the microwave energy cannot penetrate the $\mathrm{SiO}_{2}$ due to characteristics of $\mathrm{SiO}_{2}$ being non-polar. Besides that, tetrahedral structure of $\mathrm{SiO}_{2}$ is bonded by strong covalent bonding between $\mathrm{Si}$ and $\mathrm{O}$ atom and its intermolecular force is very strong which caused the microwave energy cannot absorbed by the $\mathrm{SiO}_{2}^{48}$. $\mathrm{SiO}_{2}$ particle was heated through the conduction of heat energy from carbon.

For the second stage, carbon reacted with the $\mathrm{SiO}_{2}$ particles at high temperature to form $\mathrm{SiO}$ gas (green arrows) and carbon monoxide (CO) gas (Figure $10(\mathrm{~b})$ ) and the reaction is shown in Equation (3.2) below ${ }^{49}$. This reaction is highly endothermic and required high temperature to occur.

$$
\mathrm{C}(\mathrm{s})+\mathrm{SiO}_{2}(s) \rightarrow \mathrm{SiO}(g)+\mathrm{CO}(g)
$$

$\mathrm{SiO}$ gas then further reacted with the remaining carbon to form SiCNTs with $\mathrm{CO}$ gas as the end of the reaction as shown in Figure 10 (c) in which only SiCNTs were synthesized. This reaction is shown by the Equation (3.3) as below and this was the last stage in the formation of SiCNTs in which each carbon atom in carbon molecule was bonded to 4 atoms 


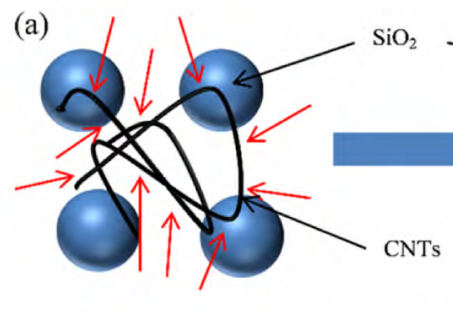

Microwave Heating (Red arrows) (b)

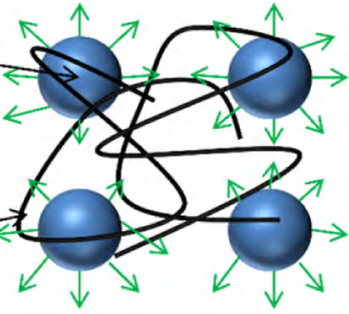

SiO gas (Green Arrows)

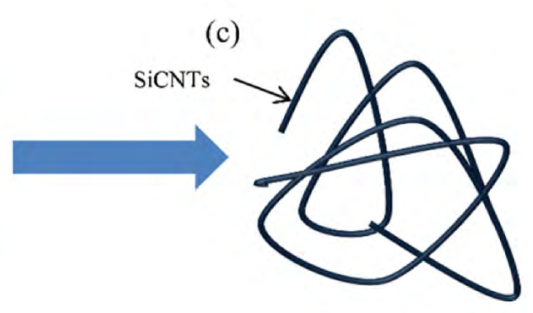

Figure 10. Schematic for the growth mechanism of $\mathrm{SiCNT}$ from blend of $\mathrm{SiO}_{2}$ and MWCNTs in the ratio of 1:1, 1:3, 1:5 and 1:7 during exposing to microwave irradiation at $1400^{\circ} \mathrm{C}$ for 40 minute with heating rate of $30^{\circ} \mathrm{C} / \mathrm{min}$.

of Si from the $\mathrm{SiO}$ gas and thus formed SiCNTs consisting of $\mathrm{Si}-\mathrm{C}$ bond structure ${ }^{50}$.

$$
2 \mathrm{C}(\mathrm{s})+\mathrm{SiO}(\mathrm{g}) \rightarrow \mathrm{SiC}(\mathrm{s})+\mathrm{CO}(\mathrm{g})
$$

This reaction of $\mathrm{SiO}_{2}$ particles and MWCNTs during the microwave heating of blend of $\mathrm{SiO}_{2}$ and MWCNTs can be concluded by overall chemical equation as shown in Equation $(3.1)^{51}$. The overall equation explained that the blend of $\mathrm{SiO}_{2}$ and MWCNTs in the ratio of 1:3 was the suitable ratio to synthesize SiCNTs.

\section{Discussion}

From the characterization and testing conducted by using XRD, FESEM, TEM, PL, FTIR, TGA and Raman spectroscopy, it can be observed that consistent results were obtained. Effective and rapid synthesis of SiCNTs can be obtained by using microwave heating assisted synthesis where special feature of the microwave heating which can rapidly produce heat through the interaction of the materials with microwave. By studying the blend ratio of the $\mathrm{SiO}_{2}$ particles and MWCNTs, high yield synthesis of SiCNTs can be achieved and thus produce high quality of SiCNTs. XRD pattern and FESEM images proved that ratio 1:3 of $\mathrm{SiO}_{2}$ particles and MWCNTs successfully synthesized high quality SiCNTs compared to others ratio in which high yield conversion of $\mathrm{SiO}_{2}$ particles and MWCNTs to SiCNTs was achieved. Similar with $\mathrm{Bi}$ et $\mathrm{al}^{25}$ in their study synthesis of SiC/MWCNTs hetero-structures, they reported that the highest formation of SiCNTs was obtained from blend of $\mathrm{SiO}_{2}$ particles and MWCNTs in the ratio of 1:3. Furthermore, Zhang et $a^{23}$ in their study of molten salt assisted synthesis of $3 \mathrm{C}-\mathrm{SiC}$ nanowires also reported that blend of $\mathrm{SiO}_{2}$ particles and carbon in the ratio of 1:3 has showed the presence of XRD peak corresponded to $\beta$-SiC with highest intensity and indicated the high yield formation of $\mathrm{SiC}$ nanowires.

Besides that, it is worth mentioning that other advantages of synthesis of SiCNTs using microwave heating in this study are the minimal usage of chemical, simple procedure, environment friendly and economical method. Although, $\mathrm{SiC}$ has been successfully synthesized through carbothermal reduction using conventional heating ${ }^{52}$ and sol-gel ${ }^{53}$ but, these processes are mainly energy consuming, require very high temperature, long heating duration and slow heating rate which in turn affect the synthesis of SiC. Obviously, the use of microwave heating for the synthesis of SiCNTs provides advantages such as rapid synthesis, simple procedure and no catalyst is required for the process. By study of the effect of ratio of raw materials, the high yield synthesis of the SiCNTs using microwave heating can be achieved and high quality SiCNTs could be obtained. This study also showed the novel way for the preparation and synthesis of SiCNTs using $\mathrm{SiO}_{2}$ particles and MWCNTs. Although, $\mathrm{Bi}$ et al and Quah et al also reported the similar study of the effect of different ratios of $\mathrm{SiO}_{2}$ particles and CNTs, in this study, we aimed to obtain high yield conversion of $\mathrm{SiO}_{2}$ particles and MWCNTs to SiCNTs by using microwave heating method which is more energy efficient and rapid comparing to conventional heating which is generally an energy and time consuming process.

\section{Conclusions}

For the first time, SiCNTs has been successfully synthesized from blend of $\mathrm{SiO}_{2}$ particles and MWCNTs in the ratios of 1:1,1:3,1:5 and 1:7 by using microwave heating as the new synthesis route which can synthesize high quality SiCNTs in a more time and energy efficient way. SiCNTs were characterized by using X-ray diffraction (XRD), field emission scanning electron microscopy (FESEM), transmission electron microscopy (TEM), photoluminescence spectroscopy (PL), fourier transform infrared (FTIR), thermal gravimetric analysis (TGA) and raman spectroscopy. The blend of $\mathrm{SiO}_{2}$ and MWCNTs in the ratio of 1:3 is the most suitable ratio for the synthesis of SiCNTs because of high yield conversion of $\mathrm{SiO}_{2}$ and MWCNTs was achieved and resulted in the formation of $\beta$-SiCNTs with only very small 
amount of residual unreacted $\mathrm{SiO}_{2}$ particles and MWCNTs. Besides that, the tubular structure of nanotube was completely retained and the band gap for SiCNTs was found to be 2.67 $\mathrm{eV}$. These results evidenced the optimal condition for the generation of SiCNTs-based nanostructures. Through the implementation of the microwave heating in synthesis of $\mathrm{SiC}$ nano-materials, it has showed the novel way for the new processing method with simple procedure, high heating rate and low consumption of energy and thus improved the quality of synthesized $\mathrm{SiC}$ nano-materials compared to the currently used conventional heating method available for the synthesis of $\mathrm{SiC}$ nano-materials.

\section{Acknowledgments}

This work was supported by the Department of Higher Education, Ministry of Higher Education, and Malaysia [FRGS 9003-00441].

\section{References}

1. Oliveros A, Guiseppi-Elie A, Saddow SE. Silicon carbide: a versatile material for biosensor applications. Biomedical Microdevices. 2013;15(2):353-368.

2. Zhou W, Yan L, Wang Y, Zhang Y. SiC nanowires: A photocatalytic nanomaterial. Applied Physics Letters. 2006;89(1):013105.

3. Mahdizadeh SJ, Goharshadi EK. Hydrogen storage on silicon, carbon, and silicon carbide nanotubes: A combined quantum mechanics and grand canonical Monte Carlo simulation study. International Journal of Hydrogen Energy. 2014;39(4):17191731.

4. Ribeiro S, Ribeiro GC, Oliveira MR. Properties of SiC Ceramics Sintered via Liquid Phase Using $\mathrm{Al}_{2} \mathrm{O}_{3}+\mathrm{Y}_{2} \mathrm{O}_{3}, \mathrm{Al}_{2} \mathrm{O}_{3}+\mathrm{Yb}_{2} \mathrm{O}_{3}$ and $\mathrm{Al}_{2} \mathrm{O}_{3}+\mathrm{Dy}_{2} \mathrm{O}_{3}$ as Additives: a Comparative Study. Materials Research. 2015;18(3):525-529.

5. Wu R, Zhou K, Yue CY, Wei J, Pan Y. Recent progress in synthesis, properties and potential applications of $\mathrm{SiC}$ nanomaterials. Progress in Materials Science. 2015;72:1-60.

6. Bosi M, Attolini G, Negri M, Frigeri C, Buffagni E, Ferrari C, et al. Optimization of a buffer layer for cubic silicon carbide growth on silicon substrates. Journal of Crystal Growth. 2013;383:84-94.

7. Károly Z, Mohai I, Klébert S, Keszler A, Sajó IE, Szépvölgyi J. Synthesis of $\mathrm{SiC}$ powder by RF plasma technique. Powder Technology. 2011;214(3):300-305.

8. Xie Z, Tao D, Wang J. Synthesis of silicon carbide nanotubes by chemical vapor deposition. Journal of Nanoscience and Nanotechnology. 2007;7(2):647-652.

9. Yang Z, Xia Y, Mokaya R. High Surface Area Silicon Carbide Whiskers and Nanotubes Nanocast Using Mesoporous Silica. Chemistry of Materials. 2004;16(20):3877-3884.

10. Latu-Romain L, Ollivier M, Mantoux A, Auvert G, ChaixPluchery O, Sarigiannidou E, et al. From Si nanowire to SiC nanotube. Journal of Nanoparticle Research. 2011;13(10):5425.
11. Latu-Romain L, Ollivier M, Thiney V, Chaix-Pluchery O, Martin M. Silicon carbide nanotubes growth: an original approach. Journal of Physics D: Applied Physics. 2013;46(9):092001.

12. van Laar JH, Slabber JFM, Meyer JP, van Der Walt IJ, Puts GJ, Crouse PL. Microwave-plasma synthesis of nano-sized silicon carbide at atmospheric pressure. Ceramics International. 2015;41(3 Pt B):4326-4333.

13. Kahar SM, Voon CH, Lee CC, Gopinath SCB, Arshad MK, Lim BY, et al. Synthesis of silicon carbide nanowhiskers by microwave heating: effect of heating duration. Materials Research Express. 2017;4(1):015005.

14. Hashimoto S, Ohashi S, Hirao K, Zhou Y, Hyuga H, Honda $\mathrm{S}$, et al. Mechanism for the formation of $\mathrm{SiC}$ by carbothermal reduction reaction using a microwave heating technique. Journal of the Ceramic Society of Japan. 2011;119(10):740-744.

15. Dzido G, Markowski P, Malachowska-Jutsz A, Prusik K, Jarzebski AB. Rapid continuous microwave-assisted synthesis of silver nanoparticles to achieve very high productivity and full yield: from mechanistic study to optimal fabrication strategy. Journal of Nanoparticle Research. 2015;17:27.

16. Galvão NKAM, Vasconcelos G, Santos MVR, Campos TMB, Pessoa RS, Guerino M, et al. Growth and Characterization of Graphene on Polycrystalline SiC Substrate Using Heating by $\mathrm{CO}_{2}$ Laser Beam. Materials Research. 2016;19(6):1329-1334.

17. Menéndez JA, Arenillas A, Fidalgo B, Fernández Y, Zubizarreta $\mathrm{L}$, Calvo EG, et al. Microwave heating processes involving carbon materials. Fuel Processing Technology. 2010;91(1):1-8.

18. Shi L, Hu X, Huang Y. Fast microwave-assisted synthesis of $\mathrm{Nb}$-doped $\mathrm{Li}_{4} \mathrm{Ti}_{5} \mathrm{O}_{12}$ for high-rate lithium-ion batteries. Journal of Nanoparticle Research. 2014;16:2332.

19. Oghbaei M, Mirzaee O. Microwave versus conventional sintering: A review of fundamentals, advantages and applications. Journal of Alloys and Compounds. 2010;494(1-2):175-189.

20. Li J, Shirai T, Fuji M. Rapid carbothermal synthesis of nanostructured silicon carbide particles and whiskers from rice husk by microwave heating method. Advanced Powder Technology. 2013;24(5):838-843.

21. Kim T, Lee J, Lee KH. Microwave heating of carbon-based solid materials. Carbon Letters. 2014;15(1):15-24.

22. Ding J, Deng C, Yuan W, Zhu H, Zhang X. Novel synthesis and characterization of silicon carbide nanowires on graphite flakes. Ceramics International. 2014;40(3):4001-4007.

23. Zhang J, Li W, Jia Q, Lin L, Huang J, Zhang S. Molten salt assisted synthesis of $3 \mathrm{C}-\mathrm{SiC}$ nanowire and its photoluminescence properties. Ceramics International. 2015;41(10 Pt B):1261412620.

24. Ding J, Zhu H, Li G, Deng C, Li J. Growth of SiC nanowires on wooden template surface using molten salt media. Applied Surface Science. 2014;320:620-626.

25. Bi S, Ma L, Mei B, Tian Q, Liu C, Zhong C, et al. Silicon carbide/carbon nanotube heterostructures: Controllable synthesis, dielectric properties and microwave absorption. Advanced Powder Technology. 2014;25(4):1273-1279. 
26. Quah HJ, Cheong KY, Lockman Z. Stimulation of silicon carbide nanotubes formation using different ratios of carbon nanotubes to silicon dioxide nanopowders. Journal of Alloys and Compounds. 2009;475(1-2):565-568.

27. Kharissova OV, Kharisov BI. Variations of interlayer spacing in carbon nanotubes. RSC Advances. 2014;4(58):30807-30815.

28. Dai JX, Sha JJ, Zhang ZF, Wang YC, Krenkel W. Synthesis of high crystalline beta $\mathrm{SiC}$ nanowires on a large scale without catalyst. Ceramics International. 2015;41(8):9637-9641.

29. Lee KM, Hwang JY, Urban B, Singh A, Neogi A, Lee SK, et al. Origin of broad band emissions of $3 \mathrm{C}$-silicon carbide nanowire by temperature and time resolved photoluminescence study. Solid State Communications. 2015;204:16-18.

30. Chen J, Tang W, Xin L, Shi Q. Band gap characterization and photoluminescence properties of $\mathrm{SiC}$ nanowires. Applied Physics A. 2011;102(1):213-217.

31. Nazarudin NFFB, Noor NJBM, Rahman SA, Goh BT. Photoluminescence and structural properties of $\mathrm{Si} / \mathrm{SiC}$ coreshell nanowires growth by HWCVD. Journal of Luminescence. 2015;157:149-157.

32. Chiu SC, Li YY. SiC nanowires in large quantities: Synthesis, band gap characterization, and photoluminescence properties. Journal of Crystal Growth. 2009;311(4):1036-1041.

33. Paul R, Kumbhakar P, Mitra AK. Synthesis and study of photoluminescence characteristics of carbon nanotube/ZnS hybrid nanostructures. Journal of Experimental Nanoscience. 2010;5(4):363-373.

34. Yu Y, Yu JC, Chan CY, Che YK, Zhao JC, Ding L, et al. Enhancement of adsorption and photocatalytic activity of $\mathrm{TiO}_{2}$ by using carbon nanotubes for the treatment of azo dye. Applied Catalysis B: Environmental. 2005;61(1-2):1-11.

35. Lam SM, Sin JC, Abdullah AZ, Mohamed AR. Photocatalytic $\mathrm{TiO}_{2} /$ Carbon Nanotube Nanocomposites for Environmental Applications: An Overview and Recent Developments. Fullerenes, Nanotubes and Carbon Nanostructures. 2014;22(5):471-509.

36. Abdullahi N, Saion E, Shaari AH, Al-Hada NM, Keiteb A. Optimisation of the Photonic Efficiency of $\mathrm{TiO}_{2}$ Decorated on MWCNTs for Methylene Blue Photodegradation. PLoS One. 2015;10(5):e0125511.

37. Gui MM, Chai SP, Xu BQ, Mohamed AR. Visible-light-driven MWCNT@TiO, core-shell nanocomposites and the roles of MWCNTs on the surface chemistry, optical properties and reactivity in $\mathrm{CO}_{2}$ photoreduction. RSC Advances. 2014;4(46):24007-24013.

38. Raman V, Bhatia G, Mishra AK, Bhardwaj S, Sood KN. Synthesis of silicon carbide nanofibers from pitch blended with sol-gel derived silica. Materials Letters. 2006;60(29-30):3906-3911.

39. Chen J, Shi Q, Xin L, Liu Y, Liu R, Zhu X. A simple catalystfree route for large-scale synthesis of $\mathrm{SiC}$ nanowires. Journal of Alloys and Compounds. 2011;509(24):6844-6847.

40. Yang X, Zhao-hui C, Feng C. High-temperature protective coatings for $\mathrm{C} / \mathrm{SiC}$ composites. Journal of Asian Ceramic Societies. 2014;2(4):305-309.
41. Giorcelli M, Pavese M, Shahzad MI, Tagliaferro A. Silicon carbide hollow cylinders using carbon nanotubes structures as template. Materials Letters. 2015;151:12-15.

42. Zhou X, Li X, Gao Q, Yuan J, Wen J, Fang Y, et al. Metal-free carbon nanotube-SiC nanowires heterostructures with enhanced photocatalytic $\mathrm{H} 2$ evolution under visible light irradiation. Catalysis Science \& Technology. 2015;5:2798-2806.

43. Pan Y, Zhu P, Wang X, Li S. Preparation and characterization of one-dimensional SiC-CNT composite nanotubes. Diamond and Related Materials. 2011;20(3):310-313.

44. Qi X, Liang J, Yu C, Ma S, Liu X, Xu B. Facile synthesis of interconnected $\mathrm{SiC}$ nanowire networks on silicon substrate. Materials Letters. 2014;116:68-70.

45. Wei J, Li K, Li H, Hou D, Zhang Y, Wang C. Large-scale synthesis and photoluminescence properties of hexagonalshaped $\mathrm{SiC}$ nanowires. Journal of Alloys and Compounds. 2008;462(1-2):271-274.

46. Czosnek C, Bućko MM, Janik JF, Olejniczak Z, Bystrzejewski M, Łabędź O, et al. Preparation of silicon carbide SiC-based nanopowders by the aerosol-assisted synthesis and the DC thermal plasma synthesis methods. Materials Research Bulletin. 2015;63:164-172

47. Nwigboji IH, Ejembi JI, Wang Z, Bagayoko D, Zhao GL. Microwave absorption properties of multi-walled carbon nanotube (outer diameter 20-30nm)-epoxy composites from 1 to $26.5 \mathrm{GHz}$. Diamond and Related Materials. 2015;52:66-71.

48. Peng Z, Hwang JY, Kim BG, Andriese M, Wang X. Microwave Dielectric Characterization of Silicon Dioxide. In: Hwang JY, Bai C, Carpenter J, Ikhmayies SJ, Li B, Monteiro SN, et al., eds. Characterization of Minerals, Metals, and Materials 2013. Hoboken: John Wiley \& Sons; 2013. p. 389-395.

49. Luo X, Ma W, Zhou Y, Liu D, Yang B, Dai Y. Synthesis and Photoluminescence Property of Silicon Carbide Nanowires Via Carbothermic Reduction of Silica. Nanoscale Research Letters. 2009;5(1):252-256.

50. Chiew YL, Cheong KY. A review on the synthesis of SiC from plant-based biomasses. Materials Science and Engineering: $B$. 2011;176(13):951-964.

51. Cetinkaya S, Eroglu S. Chemical vapor deposition of $\mathrm{C}$ on $\mathrm{SiO}_{2}$ and subsequent carbothermal reduction for the synthesis of nanocrystalline $\mathrm{SiC}$ particles/whiskers. International Journal of Refractory Metals and Hard Materials. 2011;29(5):566-572.

52. Keller N, Pham-Huu C, Ehret G, Keller V, Ledoux MJ. Synthesis and characterisation of medium surface area silicon carbide nanotubes. Carbon. 2003;41:2131-2139.

53. Najafi A, Fard FG, Rezaie HR, Ehsani N. Synthesis and characterization of $\mathrm{SiC}$ nano powder with low residual carbon processed by sol-gel method. Powder Technology. 2012;219:202210. 